\title{
La Violencia hacia las MUjeres en OAXACA. En lOS CAMinos DE LA DESIGUALDAD Y LA POBREZA
}

\author{
Violence against Women in Oaxaca. In the Ways of Inequality and Poverty
}

\author{
María Leticia Briseño-Maas \\ Eduardo Bautista-Martínez
}

\begin{abstract}
Resumen: El incremento de las manifestaciones de violencia contra las mujeres en Oaxaca y los encadenamientos de esas expresiones deben explicarse más allá de coyunturas inmediatas y en una perspectiva de interseccionalidad. Dada la amplitud de las expresiones de violencia de género y la constitución eminentemente rural e indígena del estado de Oaxaca, el presente texto se enfoca en las violencias que sufren las mujeres indígenas relacionadas con los conflictos comunitarios y agrarios, las luchas por la tenencia de tierras y su participación en los sistemas de organización tradicional, expresiones consideradas dentro de la modalidad de violencia en la comunidad.
\end{abstract}

Palabras clave: violencia hacia las mujeres, desigualdad, pobreza.

Abstract: The increase in manifestations of violence against women in Oaxaca and links between these expressions should be explained beyond immediate situations and in a perspective of intersectionality. Given the breadth of expressions of gender violence and the predominantly rural and indigenous constitution of the state of Oaxaca, this paper focuses on the nature of violence faced by indigenous women within their community, concerning land conflicts, the struggle for land tenure and the relative recent participation of women in positions of authority not traditional assumed by them.

Keywords: violence against women, inequality, poverty.

\footnotetext{
María Leticia Briseño Maas, doctora en Pedagogía por la Universidad Nacional Autónoma de México. Profesora e investigadora en el Instituto de Ciencias de la Educación de la Universidad Autónoma Benito Juárez de Oaxaca, México. Temas de especialización: educación, jóvenes y género. Correo electrónico: tishauabjo@hotmail.com.

Eduardo Bautista Martínez, doctor en Ciencias Sociales por la Universidad Autónoma Metropolitana, México. Profesor e investigador del Instituto de Investigaciones Sociológicas de la Universidad Autónoma Benito Juárez de Oaxaca, México. Temas de especialización: movimientos sociales, género y políticas públicas. Correo electrónico: ecbm00@hotmail.com.
}

Enviado a dictamen: 30 de octubre de 2015. Aprobación: 12 de febrero de 2016.

Revisiones: 1 . 


\section{Introducción}

$\mathrm{P}$ ara comprender la problemática de la violencia contra las mujeres en el estado de Oaxaca, es importante contextualizar ésta dentro de un ambiente social, político y económico adverso, en el cual conflictos de distinta índole se entrecruzan hasta alcanzar altos niveles de violencia social, que se agudizan por la pobreza, teniendo su rostro más crudo en la población denominada "vulnerable", constituida por la población indígena y migrante, y, en cuanto a grupos de sexo y edad, por las mujeres y las niñas. ${ }^{1}$

El presente trabajo tiene como fuente principal los resultados cualitativos y cuantitativos obtenidos a partir del estudio sobre las fuentes, orígenes y factores que producen y reproducen la violencia contra las mujeres en el estado de Oaxaca, trabajo que forma parte del estudio regional, coordinado por El Colegio de la Frontera Sur en cuatro estados del sureste mexicano: Chiapas, Guerrero, Yucatán y Oaxaca, ${ }^{2}$ el cual forma parte de un proyecto nacional. El objetivo del estudio consistió en conocer las causas y consecuencias de las violencias hacia las mujeres en los ámbitos comunitario, institucional, laboral, escolar y respecto a la violencia feminicida (Tuñón, Tinoco y Evangelista, 2012; Castro y Riquer, 2012).

Como resultado del análisis de los resultados obtenidos en Oaxaca, se encontró que la población femenina en este estado, particularmente la indígena, es la más afectada por la violencia de género, por lo que se tomó la decisión de abordar el contenido desde la modalidad de violencia en la comunidad, como una categoría que no excluye a las otras, sino que las aglutina en los espacios inmediatos de convivencia y amerita explicaciones más complejas que no pueden atribuirse exclusivamente a las dinámicas comunitarias.

Sobre este tipo de violencia, la Ley General de Acceso de las Mujeres a una Vida Libre de Violencia considera que corresponde a: "los actos individuales o colectivos que transgreden derechos fundamentales de las mujeres y propician su denigración, discriminación, marginación o exclusión en el ámbito público". ${ }^{3}$ Se entiende la violencia contra las mujeres como:
"Cualquier acción u omisión, basada en su género, que les cause daño o sufrimiento psicológico, físico, patrimonial, económico, sexual o la muerte tanto en el ámbito privado como en el público" (LGAMVLV, 2007: 2).

En términos teóricos e históricos, la reflexión abreva de debates sobre la condición estructural y sistémica de la violencia y sus expresiones diferenciadas entre los países y las regiones, que dan cuenta de la historia negada de las mujeres, del despojo de sus saberes y de su autonomía material (Federici, 2013). En lo que corresponde a las violencias encadenadas y su relación con la pobreza en América Latina, se recupera el aporte de violencias interseccionales (Muñoz, 2011). Asimismo, se tomaron en cuenta las recomendaciones de vincular lo teórico con lo empírico, ante el predominio de investigaciones teóricas sin datos o de casos de empirismo ciego (Castro y Riquer, 2003), que pueden adquirir concreción a partir del estudio de sus manifestaciones y causalidades específicas.

El objetivo es contribuir a la visibilización del incremento de las manifestaciones de violencia contra las mujeres en Oaxaca y los encadenamientos de esas expresiones, que deben explicarse más allá de coyunturas inmediatas y en una perspectiva de interseccionalidad, considerando que la violencia de género afecta principalmente a las mujeres y "proviene de un complejo engranaje de poder que no puede ser interpretado en su totalidad por variables aisladas, sino, por el contrario, por un enfoque integrador u holístico" (Muñoz, 2011: 8), además de que las estructuras de desigualdad socioeconómica perpetúan la subordinación y opresión de las mujeres en cualquier lugar del mundo.

El paradigma de la interseccionalidad ha sido definido como un sistema de múltiples y simultáneas estructuras de opresión en el cual la discriminación por razones de sexo, raza/etnicidad, edad, preferencia sexual y otros factores, entre los que se incluye la pobreza, interactúan generando un continuum que comprende diversas manifestaciones y gradaciones de violencia (Muñoz, 2011: 6). 
Se parte del planteamiento de que los diversos tipos de violencia que predominan en Oaxaca tienen como denominador común la desigualdad social y la pobreza, condiciones estructurales e históricas que colocan en posiciones de mayor desventaja a las mujeres, particularmente a las mujeres indígenas, considerando que esta situación es resultado de procesos sociales de larga duración, en los que la inequidad de género ha sido una constante y no puede separarse de la desigualdad social ni de la pobreza.

A mayor escala, también podría señalarse que en México y en América Latina se puede observar el incremento de las manifestaciones de violencia contra las mujeres, y que esta violencia es de carácter estructural. En términos analíticos, y de la misma manera que para el ámbito local, es importante considerar sus manifestaciones en perspectiva de interseccionalidad, a partir de un conjunto de variables asociadas.

\section{El método y las cifras negras de la violencia de género}

En la investigación original se utilizaron criterios metodológicos cuantitativos y cualitativos para analizar las causas y condiciones que originan la violencia, así como para identificar quiénes la producen.

El aporte metodológico del equipo de investigación de Oaxaca consiste en identificar las condiciones y las manifestaciones particulares de la violencia en la entidad a partir de la recuperación de los datos estadísticos de la Encuesta Nacional sobre la Dinámica de las Relaciones en los Hogares (ENDIREH) de 2006 y 2011 (INEGI, 2007 y 2013a) y de los datos aportados por los recuentos ciudadanos y por actores clave de instituciones gubernamentales e integrantes de organizaciones de la sociedad civil, quienes, a partir de sus experiencias, refirieron en las entrevistas realizadas por el grupo de investigación los problemas estructurales de pobreza y desigualdad. También se consideraron distintas expresiones culturales de los pueblos indígenas que generan condiciones para la violencia sistémica que viven las mujeres en Oaxaca, muchas de las cuales permanecen como "cifras negras" por la falta de registros oficiales y por el desconocimiento de su ocurrencia.

En un primer momento, se realizó una búsqueda de información cuantitativa a partir de las encuestas oficiales. Debido a la variación de periodos de tiempo entre esos datos y los informes ciudadanos, no fue posible hacer una comparación para establecer las relaciones o diferencias en cuanto a la información manejada. Asimismo, los datos oficiales eran insuficientes, por lo que se consideraron como referencias complementarias de análisis, más que para contrastar fuentes.

En todos los rubros de violencia se trató de buscar las fuentes primarias de las investigaciones o notas de prensa. Esto fue posible sólo en algunos casos por diversos motivos como los siguientes: los vacíos de información oficial existentes, las dificultades de efectuar diagnósticos precisos sobre el problema y la ausencia de una política pública de atención hacia este tipo de violencia de género. Estas carencias perfilan una forma de violencia institucional, en tanto que la falta de información no solamente corresponde a una omisión de las dependencias gubernamentales, sino a una invisibilización y negación de la violencia.

En un segundo momento, el equipo se dio a la tarea de realizar una selección y mapeo de los diversos actores gubernamentales y no gubernamentales cuyo objetivo era luchar contra la violencia de género desde sus ámbitos de acción. En esta etapa se realizaron entrevistas a actores clave y se obtuvieron algunos datos de las instancias oficiales. Si bien estas últimas no concentraban información sobre todos los ámbitos de violencia en los que se enfoca este estudio, sí proporcionaron datos generales.

Se consideraron además una serie de informes elaborados por organizaciones de la sociedad civil, instancias que durante varios años han dado seguimiento a las distintas modalidades de violencia contra las mujeres, como feminicidios, violencia intrafamiliar, violencia sexual, desapariciones, suicidios y violencia institucional. Debido a la falta de información, las organizaciones de la sociedad civil implementaron un seguimiento hemerográfico y han armado sus propias bases de datos a partir de los casos de violencia contra 
la mujer que aparecen en los periódicos de circulación estatal (Colectivo Huaxyacac, 2007, 2009 y 2011; Consorcio para el Diálogo..., 2015b).

En la parte cualitativa se llevaron a cabo reuniones con dos grupos focales sobre el tema y se realizaron entrevistas individuales a integrantes de organismos civiles y a algunas servidoras y servidores públicos. En las entrevistas refirieron que uno de los principales problemas a los que se enfrentan en relación con la prevención y erradicación de la violencia es la carencia de una base de datos con indicadores claros sobre violencia contra la mujer, además de que las instancias oficiales no asignan recursos económicos para este rubro ni disponen de personal capacitado para implementar un programa estadístico que permita dar un seguimiento sistemático a los casos de violencia presentados en el estado. Indicaron también el abismo que existe entre los casos de violencia denunciados y aquellos que no se llegan a reportar, es decir, las "cifras negras" u ocultas de la violencia de género.

Respecto a este problema señalaron que, si bien ha habido un reconocimiento reciente de la magnitud del problema de la violencia contra la mujer, aún falta mucho por hacer en tanto este reconocimiento rebasa la capacidad de atención que brindan las instituciones que trabajan sobre violencia por razones de género pues, además de propiciar condiciones para favorecer la denuncia, también hace falta un programa de sensibilización y profesionalización de los servidores públicos, así como un sistema de información que concentre los datos de los casos que se denuncian y que facilite el seguimiento de los mismos hasta su solución o desenlace. A pesar de las inconsistencias entre los datos que proporcionaban las diferentes fuentes, se consideró más el criterio de complementariedad que el de contrastación.

En las entrevistas se insistió en la insuficiencia del perfil y capacitación del personal que labora en las instituciones, generalmente dependencias del Instituto de la Mujer o agencias del Ministerio Público especializadas en este aspecto. Esta afirmación se desprende del reconocimiento de que los perfiles de quienes atienden casos de violencia en las instancias gubernamentales no están preparados en temáticas relacionadas con enfoque de género y responden a la improvisación. Por lo anterior, la capacitación de profesionales en el ámbito público —desde fiscales, hasta jueces o psicólogos - se convierte en determinante para que el personal proporcione mejores servicios y encauce de manera adecuada a las víctimas, contribuya a reparar daños y sancione a los responsables, considerando además que se hace necesaria la implementación de terapias de contención.

\section{El carácter sistémico de la violencia contra las mujeres}

Como se ha observado, en los casos de violencia contra las mujeres no es posible identificar un tipo o modalidad de violencia exclusiva, es decir, aquella cuyas manifestaciones no se mezclen con otros tipos o modalidades. En las historias de mujeres violentadas se detectó una cadena de tipos distintos de violencia que regularmente inician en la casa, pero que generalmente se extienden a otros espacios.

Las diversas fuentes coinciden en señalar que la violencia contra las mujeres inicia en la familia, como episodios que se naturalizan, se incrementan, son cíclicos y afectan a todo el entorno, aunque tampoco podría considerarse que son las familias las fuentes de la violencia, sino más bien los microespacios en los que se expresan deficiencias estructurales, como la desigualdad y la marginación.

Desde la experiencia de las integrantes de la Red de Violencia contra las Mujeres, ${ }^{4}$ el tipo de violencia que sufren las mujeres con las que trabajan es de tipo psicológico; sin embargo, regularmente detrás de ese tipo de violencia se encuentra también la física, la económica y la sexual, ya que es común que una mujer enfrente estos cuatro tipos de violencia a la vez. Además de lo anterior, la violencia que se ejerce contra la mujer alcanza a toda la familia debido a que es frecuente que también se produzca en contra de las hijas e hijos.

En cuanto al feminicidio, resulta relevante que se identifique como un tipo particular de violencia de género y que se desagreguen los datos relacionados con 
él, de la criminalidad en general. El reconocimiento del feminicidio es relativamente reciente, pero esimportante su enunciación como tal para procurar medidas específicas destinadas a su atención y reparación en los distintos niveles. Es en las organizaciones de la sociedad civil donde observamos mayor preocupación por la denuncia de este tipo de criminalidad (Consorcio para el Diálogo..., 2015a).

Sobre las causas de la violencia, las integrantes de la Red de Violencia contra las Mujeres señalan que son múltiples y que se relacionan con el valor que socialmente se asigna a las mujeres. En las regiones de Oaxaca prevalecen prácticas tradicionales que las desvalorizan y las colocan en inferioridad ante el hombre, entre las que se incluyen regiones como el Istmo de Tehuantepec, conocida en el folclore popular como la tierra donde mandan las mujeres. Según ellas, tampoco esta región escapa a la violencia en contra de la población femenina; de hecho, comentan que el alto nivel de alcoholismo y drogadicción en la población masculina es un factor que deriva en el aumento a agresiones contra las mujeres, que se naturalizan y se ocultan en un aparente matriarcado.

Esta cadena de violencias tiene efectos que van más allá de lo evidente; a través del perfil criminológico, se detectó que en la mayoría de las historias de vida de los agresores de mujeres está presente la violencia en el ámbito familiar, y que en su infancia fueron violentados y presenciaron agresiones a la figura materna. En este círculo de violencia también se reconoce que hay casos en los que las mujeres fueron violentadas por el esposo o pareja, y que ellas muestran su coraje a través del maltrato infantil hacia las hijas o hijos, por lo que contribuyen a reproducir los círculos o espirales crecientes de violencia (Consorcio para el Diálogo, 2015a).

De esta forma, la violencia genera violencia y sigue reproduciéndose dentro de los contextos familiares para saltar a otros ámbitos y encubrirse en distintas manifestaciones, de manera que los contextos de desigualdad y marginación se concretizan en las violencias familiares como si se tratara de asuntos privados, donde se naturalizan y regresan a los espacios públicos para perpetuarse.

\section{Mujeres indígenas y violencias encadenadas}

La idea de encadenamientos se asocia con la interseccionalidad como la expresión de un "sistema complejo de estructuras de opresión que son múltiples y simultáneas", que considera la subordinación interseccional "como la consecuencia de un factor de discriminación que, al interactuar con otros mecanismos de opresión ya existentes, crean, en conjunto, una nueva dimensión de desempoderamiento" (Muñoz, 2011: 10).

Aunque no se han definido características sociodemográficas exclusivas que reflejen el perfil de las mujeres que sufren violencia en Oaxaca, la evidencia estadística nos dice que, por su condición de vulnerabilidad, las mujeres indígenas son más propensas a enfrentar episodios de violencia a lo largo de su vida familiar y de pareja, considerando que la cuestión étnica constituye un factor que eleva los niveles de violencia hacia las mujeres de este grupo (Tuñón, Tinoco y Evangelista, 2012).

Los resultados de la ENDIREH 2011 (INEGI, 2013b) para el estado de Oaxaca dan cuenta de una serie de datos que muestran la desventaja de las mujeres desde el ámbito del hogar, en donde son objeto de violencia principalmente por sus parejas, lo que coincide con los planteamientos realizados por Castro y Riquer (2003) en el sentido de que las desigualdades sociales están asociadas con las desigualdades de género, y éstas a su vez propician mayor violencia de género, de tal manera que las manifestaciones de violencia al interior de los hogares se naturalizan y se invisibilizan en el entramado de las profundas asimetrías sociales y económicas.

Podría mencionarse que el contexto de marginación, rezago y exclusión imperante en el estado genera un ambiente de violencia social que estaría relacionado con la violencia de género, si consideramos que Oaxaca ocupa el primer lugar a escala nacional en delitos cometidos contra la mujer (INEGI, 2007 y 2013a). De lo anterior se deduce una asociación entre la desigualdad, la pobreza y la violencia de género, condiciones que inciden de manera particular en la población femenina (INEGI, 2008a y 2008b). 
Para las mujeres indígenas de Oaxaca, los datos anteriores significan un trato asimétrico que deriva en la restricción de sus libertades y del ejercicio de sus derechos, así como en índices educativos más bajos que los de los varones. Por ejemplo, en el estado la tasa de alfabetización es del $75.88 \%$ para las mujeres y del $86.97 \%$ para los hombres, mientras que la tasa de matriculación — de primaria a licenciatura - es para las mujeres del $68.53 \%$, y del $71.81 \%$ para los hombres (INEGI, 2012).

Es importante matizar que las mujeres indígenas y rurales no aceptan pasivamente la violencia sino que, en gran medida, son las personas encargadas de la procuración de justicia "las que desalientan a las mujeres para proseguir con sus denuncias" (Castro y Riquer, 2012: 23).

La modalidad de violencia hacia mujeres rurales e indígenas cobra mayor relevancia si consideramos que, en Oaxaca, las defensoras de los derechos a la tierra y el territorio, así como las defensoras de los derechos a la participación política y comunitaria de las mujeres, son quienes resienten mayores agravios en un contexto marcado por la impunidad cuando trabajan por la defensa de los recursos y los territorios comunitarios ante intereses económicos que las afectan (Consorcio para el Diálogo..., 2015a).

Respecto a las denuncias de violencia por parte de las mujeres indígenas, las organizaciones de la sociedad civil han identificado que, en los distintos ámbitos, un porcentaje alto de mujeres no denuncia las agresiones que sufre debido a factores de carácter cultural e institucional. Los factores culturales se refieren a que la violencia puede llegar a naturalizarse y aceptarse como parte de la vida cotidiana de las mujeres, y los institucionales se relacionan con los obstáculos que encuentran al acudir a las instituciones encargadas de impartir justicia, pues muchas veces se encuentran con falta de sensibilización y capacitación del personal en las distintas áreas de atención.

Para las mujeres hablantes de una lengua indígena, la denuncia se vuelve menos factible debido principalmente a dos razones: la naturalización y aceptación de la violencia ya mencionada, y la falta de orientación sobre cómo actuar, es decir, sobre las normas y sobre sus derechos, además de que desconocen cómo les afectan y no existe un marco institucional de protección y defensa. Por otro lado, en las instancias de justicia no cuentan con traductores, por lo que la comunicación con las mujeres agraviadas se complica o puede llegar a impedirse la declaración formal; y, si existen traductores, éstos suelen ser varones ya que son quienes han encontrado condiciones más favorables para el bilingüismo y el dominio de la lengua española.

\section{Sobre violencias por conflictos en la comunidad}

Respecto a la violencia en la comunidad surgida en el contexto de los conflictos entre poblaciones, se reporta que las mujeres son quienes más resienten los efectos de los conflictos sociales. Informes ciudadanos hacen referencia al conflicto político que se vive, por ejemplo, en la zona triqui, en la mixteca oaxaqueña, donde se han producido asesinatos, secuestros y emboscadas, y donde las mujeres han sido objeto de violencia sexual, secuestros y despojo de sus pertenencias, además de que se han visto forzadas a migrar hacia la capital del estado u otras entidades del país (París, 2012).

Un tipo de violencia que sufren las mujeres en Oaxaca es el fenómeno de la desaparición. Retomaremos el caso emblemático de Daniela y Virginia Ortiz Ramírez, indígenas triquis, de 14 y 20 años. Estas jóvenes desaparecieron el 5 de julio de 2007, en el tramo Putla-Juxtlahuaca de esa región y, ocho años después, en 2015, el caso sigue sin resolverse. La desaparición de Daniela y Virginia tiene como antecedentes un conflicto histórico entre comunidades que ha desencadenado actos de violencia contra las mujeres, quienes se ven afectadas por secuestros, amenazas, lesiones, violaciones, asesinatos y desapariciones (Colectivo Huaxyacac, 2009: 28; París, 2012).

Integrantes de la asociación civil Consorcio para el Diálogo Parlamentario y la Equidad de Género indican que, en esta zona de conflicto, las mujeres son asaltadas y agredidas a distintos niveles, por ejemplo, cuando acuden por el recurso que les proporciona el programa gubernamental PROSPERA Programa de Inclusión 
Social — antes Oportunidades-, ya que los agresores han identificado los días de cobro y las asaltan en el camino de regreso a sus casas. En el estado, además de la zona triqui también se ubican poblaciones como Santo Domingo Teojomulco y San Lorenzo Texmelucan, en la Sierra Sur de Oaxaca, en donde se viven situaciones similares de violencia social. En este tipo de conflictos, las mujeres quedan en condiciones de abandono y desprotección institucional, por lo que se considera que este sector de población vive los conflictos y enfrentamientos comunitarios de forma más cruel e invisibilizada.

La condición en que viven las mujeres en las comunidades, no sólo de las zonas en conflicto sino también de las poblaciones más empobrecidas del estado, es de suma violencia. En este sentido, una posibilidad que han detectado las organizaciones sociales para alcanzar cambios es formar liderazgos femeninos y fomentar la participación de las mujeres jóvenes, quienes pueden integrarse a sus poblaciones contribuyendo a la formación sobre derechos humanos. Para ello disponen de fondos de becas de estudios de nivel medio superior para jóvenes indígenas, como el que promueve el Fondo de Becas Guadalupe Musalem.

La experiencia de las instancias civiles con los liderazgos femeninos en las comunidades ha sido efectiva, sin embargo, también reconocen que las jóvenes enfrentan discriminación y agresión por la labor que realizan, pero que los logros son evidentes en el empoderamiento obtenido. Los esfuerzos son importantes, aunque estas iniciativas deberían alentarse desde las instancias gubernamentales que disponen de mayor presupuesto para incidir en políticas públicas de equidad.

\section{Violencia hacia las mujeres en los conflictos agrarios y comunitarios}

Más del 75\% del territorio del estado es de propiedad social, es decir, pertenece a comunidades, ejidos y colonias agrícolas. De este porcentaje, tres cuartas partes son tierras comunales y el resto son ejidales. La entidad tiene un importante perfil rural. De acuerdo con los resultados del Censo de Población y Vivienda 2010, el 53\% de la población de Oaxaca vive en localidades menores a 2500 habitantes (INEGI, 2010).

Entre las problemáticas más severas del estado se encuentran las luchas agrarias entre pueblos y comunidades por conflictos limítrofes, que en muchas ocasiones llegan a confrontaciones violentas y a asesinatos ante la ausencia de mecanismos adecuados de conciliación gubernamental y, en otros casos, ante la presencia de grupos de interés por el control de territorios y recursos naturales.

De acuerdo con cifras oficiales, el número de conflictos por territorio en todo el estado fluctúa normalmente entre los 450 y los 500; de este universo, 66 problemas agrarios presentan riesgo de enfrentamientos y, de ellos, 24 tienen antecedentes de violencia con saldos trágicos que incluso han afectado de manera significativa a los derechos humanos porque varias poblaciones se han visto obligadas a desplazarse, han sido privadas de sus derechos agrarios, y se ha impedido que las mujeres sean las sucesoras del derecho agrario o que accedan a los puestos de representación de los núcleos agrarios (Gobierno del Estado de Oaxaca, 2011: 114-115). Los conflictos por la defensa de la tierra han originado una violencia permanente en las zonas rurales del estado y han tenido efectos específicos en las mujeres que habitan en las áreas involucradas, efectos que se invisibilizan ante la dispersión de la violencia en las comunidades y pueblos involucrados.

Entre los efectos en la vida de las mujeres, destaca el hecho de que en muchos casos ellas se convierten en las únicas proveedoras de la familia ya que los hombres se dedican al conflicto o salen de la población para evitar involucrarse, de ahí que tengan que adoptar el rol de proveedoras, aunque no existen condiciones que les permitan realizar alguna actividad fuera de la casa. Además, para el ejercicio de este nuevo rol muchas veces no cuentan con el reconocimiento formal de sus comunidades.

En cuanto a la seguridad sobre el patrimonio, se señala que sólo el 17\% de quienes poseen derechos agrarios ejidales son mujeres, mientras que en el caso de posesionarios y avecindados el porcentaje asciende 
al 30\%. En cuanto a acceso al crédito rural, sólo lo han recibido el 14\% de las mujeres campesinas, frente al 25\% de los hombres (Gobierno del Estado de Oaxaca, 2011: 62).

Otras expresiones de violencia en las comunidades se observan en relación con su participación política en las formas de organización tradicional, en donde predominan patrones de exclusión. Como réplicas diferenciadas de lo que ocurre en la sociedad nacional, observamos también el predominio de la misoginia, de manera que se desvaloriza a las mujeres rurales e indígenas como "ciudadanas de segundas" (Olivares, 2007). El hecho de que las mujeres no puedan ejercer sus derechos políticos es una forma de violencia recurrente que afecta sobre todo a las indígenas ya que, aun siendo ciudadanas mexicanas con todos los derechos, en la realidad sólo pueden ejercer aquellos que su contexto inmediato les permite. Estas desigualdades se han expresado en los pronunciamientos derivados de los encuentros de mujeres indígenas sostenidos en 2011.

[...] es importante la participación política de las mujeres indígenas dentro de nuestras comunidades y municipios indígenas, sin importar su estado civil o condición social, porque reconocemos que el desempeño de un cargo es familiar y dual, por lo que en ocasiones puede ser representada por el padre o la madre de familia, y debe ser electa acorde a sus capacidades, para tener oportunidades equitativas. Para ello será necesario generar las condiciones para garantizar la plena participación de las mujeres (SAI, 2012: 73).

En el estado se emplean dos formas para elegir autoridades municipales: a través de partidos políticos y por el sistema de usos y costumbres. Ambas violentan los derechos políticos de las mujeres, condición que se evidencia estadísticamente, por ejemplo, en el bajo porcentaje de mujeres que ocupan cargos de presidentas municipales ya que, según datos obtenidos en las entrevistas a personal del Instituto de la Mujer Oaxaqueña, en el año 2012 sólo existían diecinueve presidentas municipales, de un total de 570 municipios.
Respecto al poder legislativo, en el congreso local la presencia femenina es mayor que en otros estados de la República, lo cual no significa que sea igualitaria, ya que la mayoría de los escaños los ocupan hombres (Bringmann, 2012: 2).

Los referentes estadísticos anteriores permiten visualizar la inequidad entre la participación de mujeres y de hombres en los cargos de representación popular. En este sentido, las organizaciones de la sociedad civil deducen que la participación política de las mujeres se limita a cubrir las cuotas requeridas a los partidos en la reforma política de 2007 y, en el caso más generalizado de la masa electora, su utilización puede favorecer intereses particulares, sin abrir verdaderos espacios para la formación de liderazgos políticos femeninos que impulsen una participación real de este sector (Conde, 2012).

Respecto a los sistemas normativos internos de los municipios, las formas de organización varían de uno a otro, y al interior de los mismos en su relación entre cabeceras y agencias municipales, por lo que en cada uno el nivel de participación de las mujeres es diferente. Aunque el asunto es complejo y amerita un conocimiento más profundo de las relaciones de género en los ámbitos comunitarios, algunos estudios destacan la exclusión de las mujeres en esos espacios; por ejemplo, se indica que, de los 418 municipios regidos por el sistema de usos y costumbres, en 43 las mujeres no tienen derecho a votar, lo que equivale al 10.3\% (Bringmann, 2012: 3).

Como refirieron en algunas entrevistas, la participación política de las mujeres en algunas comunidades indígenas se encuentra restringida porque, aunque ellas están presentes en las asambleas comunitarias, no tienen voz ni voto, a pesar de que las decisiones que toman los hombres las afectan de manera directa y tienen que cumplirlas aunque no estén de acuerdo. De la misma forma, a pesar de que las mujeres pueden contender para ser elegidas para algún cargo, cuando alguna de ellas se atreve y decide contender es rechazada o mal vista por la comunidad

Por otra parte, las mujeres que ocupan cargos públicos dentro de sus comunidades experimentan una 
sobrecarga de trabajo en el ámbito privado puesto que tienen que realizar no sólo las actividades propias de su puesto, sino las consideradas como "propias de la mujer" en la atención a su familia (Vásquez, 2011).

En el estado, la violencia contra la mujer también se observa en el régimen de partidos, como lo ejemplifica en 2004 el asesinato por motivos políticos de Guadalupe Ávila Salinas, candidata del Partido de la Revolución Democrática a la presidencia municipal de San José Estancia Grande, del que se inculpó al entonces presidente municipal de esa localidad (Martínez, 2004).

Como se aprecia, la violencia en la comunidad alcanza a todas las mujeres en general, y adquiere mayor impacto entre las mujeres indígenas, dado que en las zonas rurales las mujeres desconocen sus derechos y la violencia se encuentra naturalizada. Por lo anterior, para fortalecer la participación política de las mujeres se requiere de estructuras institucionales que les den mayor certeza, pero sobre todo de un cambio en la construcción de identidades al interior de las comunidades.

\begin{abstract}
Es necesario construir nuevas identidades que permitan y garanticen a las mujeres una vida con mayores oportunidades y libertades, para que dejen de ser esos "seres-para-otros" que viven con culpa su participación en el espacio público. La restructuración del trabajo doméstico al interior de la familia es ya un imperativo. Sin estas transformaciones, la equidad de género seguirá siendo una quimera, no sólo en los municipios usocostumbristas oaxaqueños, sino en toda la sociedad mexicana del siglo XXI (Vásquez, 2011: 267).
\end{abstract}

\section{Conclusiones}

En cuanto al posible aumento de las violencias de género, en particular hacia las mujeres, no debe partirse de que antes no existieran o de que su impacto fuera menor, sino de que con anterioridad no se habían visibilizado de manera suficiente, aunque siempre han estado presentes, sobre todo si consideramos que las raíces de la violencia son históricas y que la violencia de género no responde a coyunturas o momentos inmediatos ni es propia de situaciones imputables únicamente a personas en lo individual. Así, podemos considerar que la violencia de género afecta principalmente a las mujeres y "proviene de un complejo engranaje de poder que no puede ser interpretado en su totalidad por variables aisladas" (Muñoz, 2011: 8). En este sentido, las estructuras de desigualdad socioeconómica perpetúan la subordinación y opresión de las mujeres en cualquier lugar del mundo.

La cuestión de la interseccionalidad y la perspectiva sistémica en el análisis de las violencias de género remite a la necesidad de observar las violencias a partir de sus encadenamientos, particularmente a partir de su contexto y de su historicidad, y no como expresiones aisladas.

En los últimos años Oaxaca destaca como una de las entidades con mayor índice de violencia hacia las mujeres y se ha colocado en las estadísticas nacionales en los primeros puestos. Este tipo de violencia en el estado deriva de una múltiple discriminación: ser mujeres, ser pobres, ser indígenas, y en muchos de los casos niñas, ello añadido a habitar en uno de los estados con mayores niveles de rezago y pobreza en el país.

En cuanto a la violencia derivada de la condición indígena, este aspecto merece analizarse con una perspectiva de mayor complejidad, toda vez que no puede tratarse sin considerar el proceso de dominación colonial que ubica a la población indígena en condiciones de profundos rezagos socioeconómicos, desvalorización, discriminación y opresión, lo que ha generado encadenamientos de violencia que no son naturales de los pueblos y comunidades indígenas.

En cuanto a la violencia provocada por conflictos comunitarios, afecta particularmente a mujeres y niños ante la persistencia de intereses personalistas y partidistas que dividen a familias y pueblos enteros. Estos conflictos, en vez de resolverse, perduran en círculos viciosos, como ocurre en la zona triqui y en los pueblos de las sierras, aunque la carencia de mecanismos de conciliación gubernamental o la presencia de una legalidad selectiva y arbitraria también contribuyen a desatar violencia. 
Y la violencia hacia las personas indígenas se nutre igualmente de las ideologías autoritarias de quienes desconocen, no escuchan, no consultan e invisibilizan su existencia, porque se tiene la idea de que esos otros y otras "no saben lo que les conviene". Este tipo de violencia explota en una diversidad de conflictos locales en los que se disputan territorios, recursos naturales y futuros colectivos. Los ejemplos se multiplican a lo largo y ancho de nuestra extensa e intrincada geografía, en donde despojar de voz a las y los otros es también muestra de violencia.

Hablamos de violencias encadenadas porque las distintas modalidades - feminicida, sexual, trata de personas, violencia en el ámbito laboral o escolar y violencia por conflictos comunitarios - tienen como telón de fondo un ambiente de impunidad que configura la violencia institucional. En caso de que la desigualdad y la pobreza no se atiendan, desde la perspectiva interseccional se podría advertir el riesgo de que la violencia continúe.

Además, entre los gobiernos persiste una falta de visión intercultural y con perspectiva de género, ya que es frecuente que, por citar una modalidad, el personal de los servicios de salud en las comunidades no tenga en cuenta los elementos diferenciales de género necesarios para el control médico durante el embarazo, o que en muchos casos no se tome en cuenta que las mujeres no hablan español y, por tanto, no pueden atender las recomendaciones médicas.

En las instancias de atención a la salud y de procuración de justicia - y en todas las instituciones públicas-, debe sensibilizarse al personal, dado que aún prevalecen prácticas discriminatorias y sexistas que colocan a las mujeres en un estado de indefensión. Tanto las instancias gubernamentales como las de la sociedad civil coinciden en señalar que la violencia contra las mujeres inicia desde la familia, con episodios que se naturalizan, se incrementan, son cíclicos y afectan a todo el entorno.

Por ejemplo, desde la experiencia de las integrantes de la Red de Prevención y Erradicación de la Violencia contra las Mujeres, la violencia psicológica es la que se presenta con mayor frecuencia entre quienes buscan algún tipo de apoyo. ${ }^{5}$ Es importante señalar que, regularmente, detrás de ese tipo de violencia se encuentra la física, la económica y la sexual, ya que es común que una mujer enfrente estos cuatro tipos de violencias a la vez. También expresan que la violencia contra la mujer alcanza a toda la familia, ya que se extiende también a las hijas e hijos de estas mujeres (Briseño et al., 2011).

Las violencias andan sobre los caminos accidentados de los vacíos institucionales, en la proliferación de la pobreza que crece por doquier como hierba mala y en el ensañamiento progresivo de las violencias de género. Se materializan en quienes se ven en la necesidad de migrar y en quienes sufren desigualdad social y económica, y se nutren de las constantes violaciones a los derechos de la infancia.

Si la violencia se ha "normalizado", es urgente desandar el camino, recuperar la indignación ante sus expresiones y reeducarnos en la defensa de los derechos humanos como imperativo ético. Ello es necesario en momentos como los que vivimos, en los que la convulsión se expresa en el escalamiento de las violencias en los entrecruzamientos que van desde los espacios domésticos, comunitarios, escolares, laborales, hasta los institucionales.

Respecto a qué hacer para revertir estas condiciones, se considera un conjunto de aspectos que van del nivel macro, a partir de políticas públicas e inversiones gubernamentales con un enfoque redistributivo y el cumplimiento de derechos, al nivel micro, a partir de la formación de liderazgos en las generaciones de mujeres jóvenes quienes, tras estudiar, pueden integrarse a sus poblaciones y promover una nueva cultura de equidad para contrarrestar la naturalización de la violencia, una medida de las muchas que hacen falta. Otra más tiene que ver con la recuperación de saberes de agrupaciones de mujeres que tienen la experiencia de la lucha, de las estrategias que han emprendido a contracorriente de un sistema patriarcal que las excluye y subordina, de saberes que las han empoderado y que seguramente seguirán iluminando los caminos de otras más.

Aunque existen acciones institucionales aisladas, así como intentos de muchas mujeres por reivindicar 
su posición, el camino que queda por recorrer es largo y complejo. Otro paso consiste en insistir sobre la visibilidad del problema desde una perspectiva de género y desde la exigencia de cumplimiento de derechos, así como desde la inclusión de mecanismos de reconocimiento y atención de la diversidad cultural y etnolingüística de las mujeres, sin perder de vista la riqueza de la visión holística que ofrece la interseccionalidad o la comprensión de las distintas expresiones de violencia como procesos encadenados.

\section{Notas}

${ }^{1}$ Oaxaca, entidad del sureste mexicano, se caracteriza por registrar los indicadores de mayor rezago social y marginación en el país, así como por su alta dispersión poblacional (INEGI, 2010), elementos que convierten al estado en un espacio en donde se puede observar con claridad la violencia derivada de condiciones estructurales.

${ }^{2}$ Para dar cumplimiento a la fracción XII del artículo 42 de la Ley General de Acceso de las Mujeres a una Vida Libre de Violencia: "Realizar un Diagnóstico Nacional y otros estudios complementarios de manera periódica con perspectiva de género sobre todas las formas de violencia contra las mujeres y las niñas, en todos los ámbitos, que proporcione información objetiva para la elaboración de políticas gubernamentales en materia de prevención, atención, sanción y erradicación de la violencia contra las mujeres" (LGAMVLV, 2007: 14), se designó al Centro Regional de Investigaciones Multidisciplinarias (CRIM) de la UNAM, en coordinación con la Comisión Nacional para Prevenir y Erradicar la Violencia contra las Mujeres (CONAVIM) de la Secretaría de Gobernación, en conjunto con académicas y académicos de reconocido prestigio, para realizar dicho diagnóstico.

${ }^{3} \mathrm{Al}$ igual que a nivel nacional, en los niveles regional y estatal se recuperan de entrada las modalidades de la violencia contra la mujer propuestas por el equipo coordinador: laboral y docente, en la comunidad, institucional y feminicidio. Estas modalidades de violencia están comprendidas en las definiciones de la
Ley General de Acceso de las Mujeres a un Vida Libre de Violencia (LGAMVLV, 2007).

${ }^{4}$ La Red de Violencia contra las Mujeres está conformada por mujeres que trabajan en todas las regiones del estado en programas de erradicación de la violencia.

${ }^{5}$ La Red de Prevención y Erradicación de la Violencia contra las Mujeres está conformada por integrantes de distintas instancias gubernamentales y no gubernamentales de Oaxaca, cuyas representantes trabajan en todas las regiones del estado en programas de erradicación de la violencia.

\section{Referencias bibliográficas}

Bringmann, Julia (2011). "Participación política lejana de la realidad”. En Revista La Savia, año 1, núm. 1, junio 2012, pp. 2-3. Consorcio para el Diálogo Parlamentario y la Equidad Oaxaca.

Briseño Maas, María Leticia, Eduardo Bautista Martínez y María Guadalupe Pérez Aguilar (2011). "Estudio regional sobre las fuentes, orígenes y factores que producen y reproducen la violencia contra las mujeres en Oaxaca”. En Esperanza Tuñón Pablos, Rolando Tinoco Ojanguren y Angélica Evangelista García (coords.), Documento de trabajo del Estudio regional sobre las fuentes, orígenes $y$ factores que producen y reproducen la violencia contra las mujeres en la región sur de México. México: El Colegio de la Frontera Sur.

Castro, Roberto y Florinda Riquer (2003). "La investigación sobre violencia contra las mujeres en América Latina: entre el empirismo ciego y la teoría sin datos". En Cadernos de Saúde Pública, vol. 19, núm. 1, enero-febrero, pp. 135-146. Río de Janeiro.

Castro, Roberto y Florinda Riquer (2012). Estudio nacional sobre las fuentes, orígenes y factores que producen y reproducen la violencia contra las mujeres en la región sur de México. México: Consejo Nacional para Prevenir y Erradicar la violencia contra las mujeres, CRIM UNAM, Secretaría de Gobernación.

Colectivo Huaxyacac (2007). Feminicidio en Oaxaca. Impunidad e injusticia contra las mujeres. Oaxaca: Colectivo Huaxyacac, Centro para los Derechos de 
la Mujer Naxwiin A.C., Consorcio para el Diálogo Parlamentario y la Equidad Oaxaca A.C., et al.

Colectivo Huaxyacac (2009). Feminicidio en Oaxaca. Impunidad y crimen de Estado contra las mujeres. Informe ciudadano 2008-2009. Oaxaca: Colectivo Huaxyacac, Consorcio para el Diálogo Parlamentario y la Equidad Oaxaca A.C., et al.

Colectivo Huaxyacac (2011). Violencia contra las mujeres. Una herida abierta en Oaxaca 371 feminicidios iDónde está la justicia? 2004-2011. Oaxaca: Colectivo Huaxyacac, Consorcio para el Diálogo Parlamentario y la Equidad Oaxaca A.C., et al.

Conde, Elsa (2012). "Una agenda mínima de género y las elecciones del 2012". En Revista La Savia, año 1, núm. 1, junio, pp. 14-16. Consorcio para el Diálogo Parlamentario y la Equidad Oaxaca.

Consorcio para el Diálogo Parlamentario y la Equidad de Género, A.C. (2009). Diagnóstico: participación política y comunitaria de mujeres mixes. Oaxaca: Consorcio para el Diálogo Parlamentario y la Equidad de Género A.C.

Consorcio para el Diálogo Parlamentario y la Equidad de Género, A.C. (2015a). Defensoras de derechos humanos en la mira: desafíos para su protección integral en Oaxaca. Oaxaca: Consorcio para el Diálogo Parlamentario y la Equidad de Género A.C.

Consorcio para el Diálogo Parlamentario y la Equidad de Género, A.C. (2015b). Informe ciudadano: ausencias. Violencia feminicida y feminicidio en Oaxaca. Oaxaca: Consorcio para el Diálogo Parlamentario y la Equidad de Género A.C.

Federici, Silvia (2013). Calibán y la bruja. Mujeres, cuerpo y acumulación originaria. México: Pez en el Árbol.

Gobierno del Estado de Oaxaca 2011-2016 (2011). Plan estatal de desarrollo de Oaxaca (PED) 2011-2016. Disponible en: http://www.oaxaca.gob.mx/ wp-content/uploads/2014/11/Plan_Estatal_de_ Desarrollo_2011_2016_2.pdf (consultado el 22 de febrero de 2015).

INEGI (Instituto Nacional de Estadística y Geografía) (2007). Panorama de violencia contra las mujeres. Estados Unidos Mexicanos. ENDIREH 2006. México: INEGI. Disponible en: http:/www.unece.org/fileadmin/ DAM/stats/gender/vaw/surveys/Mexico/Mexico_
ENDIREH2006_report.pdf (consultado el 18 de agosto de 2015).

INEGI (Instituto Nacional de Estadística y Geografía) (2008a) Panorama de violencia contra las mujeres. Oaxaca. ENDIREH 2006. México: INEGI. Disponible en: http:// www.inegi.gob.mx/prod_serv/contenidos/espanol/ bvinegi/productos/estudios/sociodemografico/ mujeresrural/2007/ENDIREH06_Oaxaca.pdf (consultado el 27 de mayo de 2015).

INEGI (Instituto Nacional de Estadística y Geografía) (2008b). Mujeres en Oaxaca. Estadísticas sobre desigualdad de género y violencia contra las mujeres. México: INEGI. Disponible en: http:/www.diputados.gob.mx/ documentos/Congreso_Nacional_Legislativo/ delitos_estados/Las_Mujeres_Oaxaca.pdf (consultado el 26 de junio de 2015).

INEGI (Instituto Nacional de Estadística y Geografía) (2010). Perfil sociodemográfico Estados Unidos Mexicanos. México: INEGI. Disponible en: http://www.inegi. org.mx/prod_serv/contenidos/espanol/bvinegi/ productos/censos/poblacion/2010/perfil_socio/ uem/702825047610_l.pdf (consultado el 29 de septiembre de 2015).

INEGI (Instituto Nacional de Estadística y Geografía) (2012). Estadísticas a propósito del Día Internacional de la Mujer. Datos de Oaxaca. México: INEGI. Disponible en: $\quad$ www.inegi.org.mx/inegi/contenidos/.../ estadisticas/2012/mujer20.doc (consultado el 3 de julio de 2015).

INEGI (Instituto Nacional de Estadística y Geografía) (2013a). Panorama de violencia contra las mujeres en México. ENDIREH 201l. México: INEGI. Disponible en: http:// www.inegi.org.mx/prod_serv/contenidos/espanol/ bvinegi/productos/estudios/sociodemografico/ mujeresrural/2011/702825048327.pdf (consultado el 23 de junio de 2015).

INEGI (Instituto Nacional de Estadística y Geografía) (2013b). Panorama de violencia contra las mujeres en Oaxaca. ENDIREH 2011. México: INEGI. Disponible en: http:// www.inegi.org.mx/prod_serv/contenidos/espanol/ bvinegi/productos/estudios/sociodemografico/ mujeresrural/2011/oax/702825048860.pdf (consultado el 4 de julio de 2015). 
LGAMVLV (Ley General de Acceso de las Mujeres a una Vida Libre de Violencia) (2007). En Diario Oficial de la Federación, 1 de febrero. México: Cámara de Diputados del H. Congreso de la Unión. Disponible en: http:// www.inmujeres.gob.mx/inmujeres/images/stories/ normateca/legislacion2014/gamvlv.pdf (consultado el 5 de abril de 2015).

Muñoz Cabrera, Patricia (2011). Violencias interseccionales. Debates feministas y marcos teóricos en el tema de pobreza $y$ violencia contra las mujeres en Latinoamérica. Londres/ Honduras: Central America Women's Network.

Olivares Alonso, Emir (2007). "La participación política es casi una utopía y el mercado laboral, escaso. Mujeres indígenas, ciudadanas de segunda en Oaxaca, denuncia ONG". En La Jornada, 29 de abril. México. Disponible en: http://www.jornada.unam. $\mathrm{mx} / 2007 / 04 / 29 /$ index.php?section=politica\& $\&$ article $=$ 019nlpol (consultado el 25 de agosto de 2015).

París Pombo, María Dolores (2012). La diáspora triqui. Violencia política, desplazamiento forzado y migración. México: UAM-XOC.

SAI (Secretaría de Asuntos Indígenas del Gobierno de Oaxaca) (2012). Memoria. Primer Encuentro Estatal de
Mujeres Indígenas y Afromexicanas de Oaxaca. Oaxaca: SAI. Disponible en: http:/www.sai.oaxaca.gob.mx/ misc/doctos/pdf/MEMORIA\%20ENCUENTROVERSION\%20DIGITAL.pdf (consultado el 30 de agosto de 2015).

Tuñón Pablos, Esperanza, Rolando Tinoco Ojanguren y Angélica Aremy Evangelista García (2012). "Estudio regional sobre las fuentes, orígenes y factores que producen y reproducen la violencia contra las mujeres en la región sur de México, compuesta por los estados de Guerrero, Oaxaca, Chiapas, Campeche, Yucatán y Quintana Roo". En Comisión Nacional para Prevenir y Erradicar la Violencia contra las Mujeres (coord.), Estudio nacional sobre las fuentes, orígenes y factores que producen y reproducen la violencia contra las mujeres. Estudios regionales, t II, vol. II, cap. VI, pp. 409-695. Disponible en: http://www.conavim. gob.mx/work/models/CONAVIM/Resource/103/1/ images/EstudiosRegionalesTomo2volumen2.pdf (consultado el 30 de agosto de 2015).

Vásquez García, Verónica (2011). Usos y costumbres y ciudadanía femenina. Hablan las presidentas municipales de Oaxaca. 1996-2010. México: Miguel Ángel Porrúa. 